\title{
Strategies for reversing the effects of metabolic disorders induced as a consequence of developmental programming
}

\author{
M. H. Vickers ${ }^{1 *}$ and D. M. Sloboda ${ }^{1,2,3,4}$ \\ ${ }^{1}$ National Research Centre for Growth and Development, Liggins Institute, University of Auckland, Auckland, New Zealand \\ 2 Department of Biochemistry and Biomedical Sciences, McMaster University, Hamilton, ON, Canada \\ ${ }^{3}$ Department of Obstetrics and Gynecology, McMaster University, Hamilton, ON, Canada \\ ${ }^{4}$ Department of Pediatrics, McMaster University, Hamilton, ON, Canada
}

Edited by:

Catalina Pico, University of the

Balearic Islands, Spain

Reviewed by:

Nina Eikelis, Baker IDI Heart and

Diabetes Institute, Australia

Marianne Tare, Monash University,

Australia

*Correspondence:

M. H. Vickers, National Research

Centre for Growth and Development,

Liggins Institute, University of

Auckland, 2-6 Park Avenue, Grafton,

Auckland 1142, New Zealand.

e-mail:m.vickers@auckland.ac.nz

Obesity and the metabolic syndrome have reached epidemic proportions worldwide with far-reaching health care and economic implications. The rapid increase in the prevalence of these disorders suggests that environmental and behavioral influences, rather than genetic causes, are fueling the epidemic. The developmental origins of health and disease hypothesis has highlighted the link between the periconceptual, fetal, and early infant phases of life and the subsequent development of metabolic disorders in later life. In particular, the impact of poor maternal nutrition on susceptibility to later life metabolic disease in offspring is now well documented. Several studies have now shown, at least in experimental animal models, that some components of the metabolic syndrome, induced as a consequence of developmental programming, are potentially reversible by nutritional or targeted therapeutic interventions during windows of developmental plasticity. This review will focus on critical windows of development and possible therapeutic avenues that may reduce metabolic and obesogenic risk following an adverse early life environment.

Keywords: developmental programming, obesity, metabolic syndrome, maternal nutrition, leptin, insulin resistance, animal models

\section{INTRODUCTION}

Obesity is a serious health issue in the developed world and is becoming increasingly important on a global scale. Multiple systems regulate energy homeostasis and there is strong evidence for a genetic component to human obesity as a number of genes associated with human obesity have been identified (Hofbauer, 2002; Bell et al., 2005). However, a genetic component to obesity cannot account for the dramatic increase in the prevalence of obesity in recent years. It is a widely held view that the primary cause of obesity and related metabolic disorders in the general population is due to the ease of access to highly calorific food and reduced energy expenditure in work and leisure activities (Bell et al., 2005). However, it is now well established that events that occur during critical developmental windows influence obesity risk with epidemiological, experimental, and clinical data showing that the risk of developing disease in later life is dependent upon early life conditions. In particular, altered maternal nutrition, including undernutrition and overnutrition, can lead to metabolic disorders

Abbreviations: ARH, arcuate nucleus of the hypothalamus; $\mathrm{BBB}$, blood brain barrier; DEX, dexamethasone; Fas, fatty acid synthase; Flk-1, vascular endothelial growth factor receptor 2; GH, growth hormone; GLP-1, glucagon-like peptide 1; IGF-I, insulin-like growth factor I; IGF-II, insulin-like growth factor II; IUGR, intrauterine growth restriction; MLP, maternal low protein; PARs, predictive adaptive responses; PDX1, pancreatic and duodenal homeobox 1; PGC-1, peroxisome-proliferator-activated receptor-gamma co-activator-1; PPAR, peroxisome proliferator-activated receptor; SGA, small for gestational age; SL, small litter; SOCS-3, suppressor of cytokine signaling-3; STAT-3, signal transducer and activator of transcription 3; UN, undernutrition; VAT, visceral adipose tissue; VEGF, vascular endothelial growth factor; WAT, white adipose tissue. in offspring characterized by obesity and leptin resistance (Ravelli et al., 1999; Godfrey and Barker, 2000; Breier et al., 2001). The mechanisms underlying such associations and the relative role of genetic versus environmental factors however, remain speculative. Adaptive responses made by a fetus to an adverse intrauterine environment results in new physiological set points aimed at maximizing immediate chances for survival. These adaptations may include resetting of metabolic homeostasis and endocrine systems and the down-regulation of growth which is commonly reflected in an altered birth phenotype. The "predictive adaptive response" (PAR) hypothesis proposes that the degree of mismatch between the pre- and postnatal environment is a major determinant of subsequent disease (Gluckman and Hanson, 2004a; Gluckman et al., 2008). Thus, it is thought that whilst adaptive changes in fetal physiological function may be beneficial for short term survival in utero, these changes may be maladaptive in postnatal life and contribute to poor health outcomes particularly when offspring are exposed to catch-up growth, diet-induced obesity and other environmental factors (Gluckman and Hanson, 2004b; Gluckman et al., 2008). These so-called PARs are therefore proposed to be not merely side-effects of growth restriction in utero, but are a strategy designed to optimize the physiology of the offspring for the postnatal environment it is most likely to experience, that is, the "predicted" environment.

\section{DEVELOPMENTAL PROGRAMMING OF OBESITY AND} METABOLIC DISORDERS - EVIDENCE FROM EPIDEMIOLOGY

Barker and colleagues demonstrated a relationship between low birth weight and an increased risk of hypertension, obesity, insulin 
resistance, and dyslipidemia in later life (Barker et al., 1989, 1990; Osmond et al., 1990). From these initial observations, the importance of maternal nutrition and, in particular the effect of poor maternal nutrition on birth weight and adult disease risk was addressed in human studies of famine exposure. The most widely reported of these being the Dutch Hunger Winter of 1944-1945 (Ravelli et al., 1976, 1999; Roseboom et al., 1999, 2001); demonstrating that the timing of the exposure was a major determinant in phenotypic outcomes. Whereas famine exposure during early gestation was associated with adult hypertension (Ravelli et al., 1976), reduced maternal famine during late gestation was associated with an increased adult adiposity and glucose intolerance (Law et al., 1992; Ravelli et al., 1999). Famine exposure late in pregnancy led to a greater impairment of glucose tolerance than during early or mid-gestation. The rate of obesity was higher in men exposed in the first half of gestation and lower in men exposed in the last trimester of gestation as compared to non-exposed men. These relationships however do not speak to causation and other reports of prenatal famine exposure have yielded contradictory results. Retrospective studies investigating offspring exposed to famine during the siege of Leningrad did not show any relationship between birthweight and adult metabolic sequelae (Stanner and Yudkin, 2001). The disparity between the Dutch and the Leningrad studies may be explained using the PARs framework. Following the short period of the Dutch Winter Hunger, food supply was returned to normal levels and maternal nutrition restored; thus in many pregnancies fetuses would have been acutely "starved" in utero and subsequently well nourished in postnatal life. This may represent a circumstance that the PARs hypothesis may would describe as a nutritional mismatch between the intrauterine and postnatal - the actual and the predicted - environments. Conversely, in the Leningrad cohort, maternal nutritional status was poor both before and after pregnancy and thus one can speculate that any fetal adaptations may have been appropriate for the predicted postnatal environment.

In historically undernourished, recently urbanized populations such as India, where low birth weight individuals are exposed to a high-fat Western diet, the incidence of obesity and type 2 diabetes is reaching epidemic proportions (Yajnik, 2000). Work by Yajnik and colleagues have shown that although Indian babies are born low birth weight, they exhibit increased visceral adiposity (Yajnik, 2000). This is consistent with other studies, that have demonstrated in small babies a disproportionate abdominal fat mass during adult life, despite a lower body mass index (BMI; McMillen et al., 2005). Although there is considerable debate regarding whether accelerated postnatal growth after fetal growth restriction (catch-up growth) in early postnatal life is beneficial or not, most studies suggested that postnatal "catch-up" growth is associated with adverse outcomes in later life (Eriksson et al., 1999; Ong et al., 2000). Interestingly, work by Parsons et al. (2001) found that men with a lower birth weight, who then exhibited catch-up growth to achieve a greater proportion of their adult height by age 7, had a risk of obesity comparable to that of men with higher birth weights. Work by Eriksson et al. (2003) has demonstrated that ponderal index at birth was a reliable predictor of later obesity and also found that an early adiposity rebound in babies born of low birth weight was associated with obesity in adult life.

\section{DEVELOPMENTAL PROGRAMMING OF OBESITY - EVIDENCE FROM ANIMAL STUDIES}

Animal models have been extensively used to provide empirical data to support the developmental origins of health and disease $(\mathrm{DOHaD})$ hypothesis and essential to the search for the mechanistic links between early life influences and disease risk in later life. Although epidemiological data suggest that developmental programming occurs within the normal range of birth size (Barker, 2007a,b), most experimental models tend to significantly restrict fetal growth; in the past there was an assumption that those insults that impair fetal growth are likely to be those that trigger developmental programming. Several approaches have been developed to induce early growth restriction in animals in an attempt to elucidate the relationship between growth restriction and adult disease risk, potentially providing a framework for investigating underlying mechanisms. However, intrauterine growth restriction (IUGR) is not essential to developmental programming, but is merely a surrogate for evidence that fetal development may have been affected. Fetal growth restriction is either present or absent in experimental studies depending on the species used and the insult; impaired adult metabolic function is consistent regardless of the presence or absence of growth restriction. In the rat, obesity and metabolic disorders have been induced in offspring by maternal global undernutrition (Woodall et al., 1996a; Vickers et al., 2000, 2001, 2002; McArdle et al., 2006), maternal protein restriction (LangleyEvans et al., 1999), maternal uterine artery ligation (Rajakumar et al., 1998; Simmons et al., 2001), maternal synthetic glucocorticoid treatment (Nyirenda et al., 1998), maternal anemia (Lewis et al., 2001), or prenatal cytokine exposure (Dahlgren et al., 2001).

\section{MATERNAL UNDERNUTRITION}

The early work of Barker and colleagues highlighted fetal nutrition as the primary factor driving the developmental origins of adult disease. Within the laboratory, fetal undernutrition is most commonly achieved through maternal dietary restriction during pregnancy. At present, rodent models investigating the mechanistic links between maternal undernutrition and adult disease risk generally utilize one of two dietary protocols; global undernutrition or isocaloric low protein diets. The maternal low protein (MLP) diet during pregnancy and lactation is one of the most extensively utilized models of nutritional programming (Snoeck et al., 1990; Langley and Jackson, 1994; Desai et al., 1996; Ozanne et al., 1999; Petry et al., 2001). In this model, pregnant rats are fed ad libitum a low protein diet containing $5-8 \%(\mathrm{w} / \mathrm{w})$ protein (casein), generally a little under half the protein content but equivalent in energy of a control diet containing 18-20\% (w/w) protein (Snoeck et al., 1990; Langley-Evans, 2000). Offspring from protein-restricted mothers are 15-20\% lighter than controls at birth (Desai et al., 1996). Maintenance of a MLP diet during the period of lactation increases this weight difference and permanently limits later growth. If MLP offspring are cross-fostered at birth to lactating mothers fed a control diet, they exhibit rapid catch-up growth (Desai et al., 1996). This catch-up growth appears to have a detrimental effect on life span, which results in premature death that is associated with accelerated loss of kidney telomeric DNA (Jennings et al., 1999).

The experimental observations made in the MLP diet model point toward a number of potential mechanisms that may underlie 
the pathogenesis of obesity and diabetes in these offspring; including both structural and functional changes to a number of organ and endocrine systems. Gene ontogeny analysis of visceral adipose tissue (VAT) demonstrated a global up-regulation of genes involved in carbohydrate, lipid, and protein metabolism in offspring of MLP animals; indicative of dynamic changes in the transcriptional profile of key metabolic genes. These observations are limited by the fact that a MLP diet is isocaloric compared to the normal protein control diet and therefore by default contains an increased fat and carbohydrate content because of passive overconsumption on the MLP diet to reach protein targets (Sorensen et al., 2008).

Global maternal undernutrition models have been developed with a number of different levels of undernutrition during different periods of pregnancy. In the rat, moderate nutritional restriction ( $70 \%$ of normal intake) in the first 18 days of pregnancy resulted in offspring with significant IUGR, but offspring body weight catches up to that of controls by postnatal day 20 (Ozaki et al., 2000). These offspring displayed characteristics of insulin and leptin resistance These abnormalities increase with age and are most pronounced in male offspring (Ozaki et al., 2000) and the postnatal phenotype is markedly exacerbated when the offspring are fed a high-fat diet post-weaning. Consistent with the MLP model, transcriptional profiling in the UN model demonstrated that maternal undernutrition induced metabolic programming, favoring fat as an energy source and resulted in mitochondrial dysfunction affecting postnatal hepatic function and subsequently, via the resultant metabolic changes in other organs, leads to the evolution of a phenotype similar to that of the metabolic syndrome (Morris et al., 2009).

We have developed rodent models using global maternal undernutrition (UN) throughout pregnancy (Woodall et al., 1996b; Vickers et al., 2000). When dams are fed 30\% of ad libitum intake throughout pregnancy, i.e., a severe level of UN, offspring birthweights and placental weights were 25-30\% lower than offspring of control fed mothers. These offspring display increased adiposity, hypertension, hyperinsulinemia, hyperleptinemia, reduced locomotor activity, and hyperphagia in adult life (Vickers et al., 2000, 2003; Krechowec et al., 2006). When the degree of UN is reduced to a more moderate level, i.e., $50 \%$ of ad.libitum, offspring still display a significant level of obesity in postnatal life. A reduction to $20 \%$ of ad libitum intake during early pregnancy results in hyperinsulinemia, increased total caloric intake and changes in weight gain in a sex-specific manner with males, but not females, showing increased body weight gain (Palou et al., 2010; Garcia et al., 2011). Of note, if pre-weaning catch-up growth in offspring is prevented by maintaining the mothers on the restricted diet throughout lactation, offspring do not develop an obese phenotype (Desai et al., 2005; Howie et al., 2011). This is similar to the MLP model where continuation of the LP diet into lactation prevents the development of the metabolic phenotype, once again highlighting the possible adverse consequences of catch-up growth (Desai et al., 2005).

In addition to caloric and protein restriction models, specific micronutrient deficiencies have also been investigated. The effect of maternal iron deficiency results in several features of the metabolic syndrome in offspring (Lewis et al., 2001, 2002). Work by
Gambling et al. (2003) has highlighted that the timing of iron supplementation is critical in reversing the effects of maternal anemia on the developing fetus and postnatal sequelae in offspring. These data correlate well with human studies showing that iron supplementation during pregnancy leads to a higher mean birth weight and reduced incidence of low birth weight infants (Cogswell et al., 2003). Maternal chromium restriction significantly increased body weight and fat percentage, especially central adiposity, in both male and female rat offspring (Padmavathi et al., 2010a,b). Maternal magnesium restriction can predispose rat pups to insulin resistance and glucose intolerance (Venu et al., 2005). Maternal total vitamin restriction increases body fat content but not insulin resistance in rat offspring up to 6 months of age (Venu et al., 2004). Conversely, high multivitamin intake during pregnancy has been shown to program the male offspring who go on to demonstrate characteristics of the metabolic syndrome in adulthood, possibly through its effects on central mechanisms of food intake control (Szeto et al., 2008).

\section{MATERNAL NUTRITION EXCESS}

Epidemiological studies have demonstrated that fetal growth restriction correlates with adult disease, implying that fetal nutritional deprivation is a strong stimulus for programming (Armitage et al., 2005). As such, experimental animal models were developed using controlled maternal caloric intake or protein or macronutrient deficiency. However, in many developed societies, maternal and postnatal caloric intake is either sufficient or excessive. A number of studies have shown that the relationship between birth weight and obesity risk is not a simple inverse linear association but is a U-shaped curve; a higher prevalence of adult obesity occurs in individuals in low or high birth weight categories and this has often been attributed to both low and high planes of maternal nutrition (Armitage et al., 2005; McMillen et al., 2005; Samuelsson et al., 2008; Howie et al., 2009; Morris and Chen, 2009). Indeed in pregnancies which have been complicated by maternal diabetes, gestational diabetes, or impaired glucose tolerance, offspring have been shown to be at greater risk of developing obesity (Holemans et al., 2004). There is a similarity in offspring phenotypes derived from both ends of the maternal nutritional spectrum; offspring of both under- and over-nourished mothers display common metabolic derangements including obesity and insulin resistance. The components of the maternal diabetic and/or obesogenic environment that mediate the detrimental effects on hypothalamic appetite control and consequently offspring health are not clearly established. A common phenotypic outcome across a range of programming models is resistance to leptin in adulthood resulting in a loss of inhibition of food intake (Ozanne, 2011). However, there has been less focus on whether leptin resistance develops during the very early stages of life, at a time when leptin itself has no effect on food intake, but may play a mechanistic role in metabolic programming (Mistry et al., 1999; Glavas et al., 2010).

Maternal obesity in the rat has been shown to reprogram hypothalamic appetite signaling pathways and leptin signaling at birth (Morris and Chen, 2009). These hypothalamic changes, together with lower leptin levels in offspring of obese mothers may contribute to the lower expression of key appetite regulators at birth, suggestive of altered fetal neuronal development in 
response to maternal obesity. These alterations may contribute to eating disorders later in life. Activation of STAT-3 signifies leptin sensitivity and recent work in female rats by Shin et al. (2012) has shown that at birth, despite IUGR offspring being hypoleptinemic, hypothalamic leptin signaling was activated as seen by enhanced STAT-3. Further, it has been shown that offspring of high-fat fed (HF) dams exhibit an alteration in hypothalamic leptin-dependent STAT-3 phosphorylation, independent of the level of post-weaning nutrition (Ferezou-Viala et al., 2007).

It is notable that evidence for the programming of obesity and several other features of the metabolic syndrome from both nutrient restriction (caloric, protein, iron) and fat-feeding studies, suggest a possible commonality of mechanism (Armitage et al., 2004).

\section{CRITICAL WINDOWS FOR INTERVENTION}

Until recently, developmental programming was seen to be an irreversible change in developmental trajectory, the consequences of which had to be managed, e.g., obesity and Type 2 diabetes. Few studies have addressed the possibility of reversibility or prevention of the postnatal programmed phenotype.

The adipokine leptin has received significant interest as a potential programming factor; alterations in the profile of leptin in early life are associated with altered susceptibility to obesity and metabolic disorders in adulthood. Maintenance of a critical leptin concentration during early development facilitates the normal maturation of tissues and signaling pathways involved in metabolic homeostasis. A period of relative hypoor hyperleptinemia during this window of development will induce some of the metabolic adaptations which underlie the developmental programming of appetite control and metabolic function.

It has now been shown in a range of animal models and a number of species that perturbations in the profile of leptin in early life are associated with altered susceptibility to obesity and metabolic disorders in adulthood. It has been proposed that deficiencies in leptin during critical windows of development could lead to a hardwiring of obesity (Horvath and Bruning, 2006). Manipulation of early life leptin concentrations in animal models using exogenous leptin and/or leptin antagonists have clearly shown a role for leptin in determining metabolic fate in later life (Vickers, 2007; Attig et al., 2008a). The source of leptin during this critical developmental window may be varied and likely includes maternal transplacental transfer of leptin, endogenous fetal leptin but may also include milk leptin during lactation. Leptin in maternal milk is likely an important factor in the maturation of organ systems and feeding pathways in the neonate. Breast milk leptin correlates positively with maternal plasma leptin concentrations although the concentration in breast milk is significantly lower than that found in maternal plasma (Ucar et al., 2000). Breast fed infants have higher serum leptin levels compared to formula fed infants; and formula fed infants may be at an increased risk of developing obesity (Savino et al., 2009). Experimentally, oral intake of physiological doses of leptin during lactation in rats has been shown to prevent obesity in later life (Pico et al., 2007) supporting the hypothesis that milk leptin plays a favorable role in developmental programming.
In adult mammals, leptin acts on the brain to reduce food intake by regulating the activity of neurons in the arcuate nucleus $(\mathrm{ARH})$. Bouret et al. have shown that neural projection pathways from the ARH are permanently disrupted in leptin-deficient $o b / o b$ mice (Bouret and Simerly, 2004; Bouret et al., 2004a). Treatment of $o b / o b$ neonates with exogenous leptin rescues the development of ARH projections, and leptin promotes neurite outgrowth from ARH neurons in vitro. It is well established that small for gestational age (SGA) neonates have diminished cord blood leptin concentrations and as children are hypoleptinemic (Iniguez et al., 2004). These children go on to develop obesity and leptin resistance in adult life; which can be mimicked experimentally in the rat (Vickers et al., 2000). Thus, perinatal nutritional perturbations that alter leptin levels may have enduring consequences for the formation and function of neuronal circuits that regulate food intake and body weight (Elmquist et al., 1998; Bouret and Simerly, 2004; Bouret et al., 2004a,b). Leptin treatment to neonatal female rats born to undernourished mothers prevented the development of metabolic compromise in adulthood (Vickers et al., 2005). The complete normalization of the programmed metabolic phenotype by neonatal leptin treatment implied that leptin can reverse prenatal adaptations resulting from fetal undernutrition. Moreover, the effects were specific to low birth weight animals, whilst leptin had no effect in animals born to control mothers. Whether this leptin effect acts centrally or peripherally is unclear - one possibility is that the window of developmental plasticity is still open and the high leptin levels reverse the cuing effects of prenatal undernutrition (Gluckman et al., 2007). Consistent with this, neonatal leptin treatment to IUGR piglets partially reversed the growth restricted phenotype by correcting growth rate, body composition, and development of several organs involved in metabolic regulation (Attig et al., 2008b). It has recently been reported that intranasal leptin reduces appetite and induces weight loss in rats with diet-induced obesity (Schulz et al., 2011) but this approach has yet to be utilized in the context of developmental programming. It must be noted however that in rodents the projections of neurons in the ARH to the paraventricular nucleus, dorsomedial nuclei, and lateral hypothalamic area, areas that also influence appetite regulation, develop postnatally and correspond to a period of late gestation in the sheep and human (Muhlhausler et al., 2008).

The use of a leptin antagonist in early life mimics the effects of maternal caloric restriction. Attig et al. (2008a) administered a specific ObRb antagonist that blocked leptin's action in the neonatal rat, later predisposing offspring to leptin resistance and increased body weight gain when fed a high energy diet postnatally. Further work using leptin antagonists has shown that postnatal leptin is necessary for maturation of numerous organs in the newborn rat (Attig et al., 2011) with leptin antagonism resulting in aberrant pancreas, kidney, and ovarian development. We have shown that administration of pegylated leptin antagonist (increased half life compared to standard leptin antagonist) to rat neonates can also modify their responsiveness to diet-induced obesity in adult life but this is dependent upon prior maternal nutrition and post-weaning diet (Beltrand et al., 2012).

Pregnancy is characterized by a state of leptin resistance comprising an adaptive response that facilitates maternal energy 
storage in preparation for the high metabolic demands of pregnancy and subsequent lactation (Ladyman et al., 2010). However, despite resistance to the central anorectic effects of leptin, it has also been reported that maternal leptin treatment to dams fed a low protein diet can prevent the adverse metabolic programming induced as a consequence of protein malnutrition (Stocker et al., 2004). Increased exposure of the fetus to maternally derived glucocorticoids has been established as a mechanism regulating metabolic demise in offspring; indeed leptin administration in models of low maternal protein intake resulted in the normalization of placental 11 $\beta$-hydroxysteroid dehydrogenase-2 (11 $\beta$-HSD2) levels (Stocker et al., 2004), resulting in a potential reduction in fetal exposure to maternal glucocorticoids. Of note, leptin administration to normally nourished dams also conferred protection against diet-induced obesity in offspring (Stocker et al., 2007) suggesting that effects may be independent of maternal dietary intake.

Maternal supplementation with methyl donors has also been reported to modify some deleterious effects of programming on offspring. Maternal folic acid supplementation in the rat following protein restriction prevents epigenetic modification of hepatic gene expression in the offspring including PPAR- $\alpha$ and $-\gamma$ (Lillycrop et al., 2005). Whether the reversal of hypomethylation in this setting improves metabolic outcome in offspring is not known. A recent study using a similar model reported that maternal protein and folic acid intake during gestation does not program leptin transcription or circulating leptin concentrations in rat progeny (Chmurzynska et al., 2011). Maternal glycine (Jackson et al., 2002) and choline (Bai et al., 2012) supplementation can also prevent MLP-induced hypertension in offspring in adulthood although the mechanisms are not yet fully understood.

The role of catch-up growth on development of the adult obese phenotype is still under debate. Work by Plagemann (2006) argued that it may not be fetal undernutrition and low birth weight per se that predisposes to adult-onset obesity; rather it is the overfeeding of underweight newborns that may substantially contribute to their long-term disease risk. When IUGR offspring are permitted rapid catch-up growth by nutrient availability, these offspring will demonstrate evidence of increase body weight and body fat, and leptin resistance as adults. Conversely, if catch-up growth is delayed by postnatal nutrient restriction, these offspring exhibit normal body weight, body fat, and plasma leptin levels as adults (Desai et al., 2005; Howie et al., 2011). However, in contrast to the observations by Lopez et al. (2007) have reported that perinatal overfeeding (using small litters, SL) does not induce alterations in either the anorectic response to central leptin administration or expression of leptin receptors and neuropeptides in adult rats. The leptin resistance to peripheral leptin in adult SL rats may be related to impaired leptin transport across the BBB. This transport mechanism could be triglyceride-mediated as reported by Banks et al. (2004). SL offspring have significantly elevated plasma triglycerides as adults (Plagemann et al., 1999). As triglycerides inhibit the transport of leptin across the BBB they could be a key factor in the onset of the peripheral leptin resistance, which is a hallmark of obesity.

Although leptin treatment has beneficial effects in ameliorating metabolic disorders that result from developmental programming, leptin treatment to offspring of normal pregnancies may have adverse long-term metabolic effects which may relate to alterations in the amplification and timing of the neonatal leptin surge (Itoh et al., 2011). Itoh et al. (2011) showed that giving neonatal leptin treatment to control mice lead to impaired glucose tolerance in adult offspring. In the rat, the effects of exogenous leptin in male offspring are directionally dependent upon maternal nutritional status (Vickers et al., 2008). A study by Yura et al. (2005) showed that treatment of male control offspring with leptin in the neonatal period resulted in a modest increase in the risk for obesity as compared to saline treated controls. This concurs with a previous study of leptin given to normal neonatal rats which also showed programmed hyperleptinemia and hyperinsulinemia in adulthood, and lead to leptin resistance by reducing the expression of the hypothalamic leptin receptor (Toste et al., 2006). However, work by Pico et al. (2011) has shown that oral administration of leptin at physiological doses to rat neonates had later positive metabolic effects that prevented development of overweight and obesity. Thus, studies in rodents suggest that early leptin treatment may program either a later lean or obese phenotype. These differences in metabolic outcomes across studies may relate in part to the dosage used, source of leptin, gender, and method of administration (Pico et al., 2011).

Interventional studies in humans demonstrate that leptin administration in subjects with congenital complete leptin deficiency or subjects with partial leptin deficiency (subjects with lipoatrophy, congenital or related to HIV infection, and women with hypothalamic amenorrhea) reverses the energy homeostasis and neuroendocrine and metabolic abnormalities associated with these conditions (Chan et al., 2011; Mantzoros et al., 2011). In contrast, leptin's effects are largely absent in the obese hyperleptinemic state, primarily as a result of leptin resistance or tolerance (Mantzoros et al., 2011). However, failure of leptin in the clinic as an intervention in obesity, and withdrawal of numerous anti-obesity drugs from clinical use, e.g., sibutramine, has stimulated new approaches in the development of anti-obesity drugs. These efforts are focused on utilizing leptin-related synthetic peptides as leptin receptor antagonists or leptin-related synthetic peptide analogs or mimetics (Grasso, 2011).

The current animal data fit with the PAR hypothesis proposed by Gluckman and Hanson (2004a). Following the PAR hypothesis, in response to a given in utero or early postnatal nutritional plane (either high or low), cellular processes are invoked to cope with the predicted environment. This hypothesis suggests that disease only manifests when the actual nutritional environment diverges from that which was predicted. Since the development of critical pathways involved in energy homeostasis in rodents continue well into the postnatal period, it can be modified by both preand postnatal environmental manipulation (e.g., prevention of catch-up growth) and thus obesity can be potentiated, reversed, or attenuated postnatally. It is likely that similar principles hold true for humans although the timing of pathway development occurs earlier than in rodents.

Work in the rodent has shown that treatment with both growth hormone (GH) and insulin-like growth factor (IGF)-I can resolve several aspects of the metabolic phenotype in developmentally programmed offspring. In a model of maternal undernutrition to induce fetal growth restriction, offspring fed either a control 
or high-fat diet postnatally demonstrated hypertension, obesity, hyperphagia, hyperinsulinemia, and hyperleptinemia; the effects of which were markedly amplified in the presence of a postnatal high-fat diet (Vickers et al., 2000). Adult treatment with GH normalized systolic blood pressure and reduced fat mass but simultaneously exacerbated the hyperinsulinemia as a result of the diabetogenic actions of GH (Vickers et al., 2002). IGFI infusion in adult females led to a complete normalization of adiposity, appetite, fasting plasma insulin, and leptin concentrations in developmentally programmed offspring (Vickers et al., 2001). These studies highlight the role of the somatotropic axis in metabolic disturbances although the longer term efficacy of such treatment regimes is not known. Trials with GH in small for gestation age children have shown a normalization in systolic blood pressure which was maintained for the 6 year duration of treatment (Holemans et al., 2004).

Epidemiological and experimental studies have shown that early life adversity leads to glucose intolerance and an enhanced risk for type 2 diabetes in offspring. Work by Simmons et al. has shown that treatment of neonatal rats with the glucagon-like peptide (GLP)-1 analog Exendin-4 (EX-4) reversed the adverse consequences of being born growth restricted and prevented the development of diabetes in adulthood (Stoffers et al., 2003; Park et al., 2008; Raab et al., 2009). Neonatal EX-4 prevented the progressive reduction in insulin-producing $B$-cell mass that was observed in IUGR rats over time and restored to normal levels the expression of pancreatic duodenal homeobox (PDX), a critical regulator of pancreas development and islet differentiation. It has recently also been shown that EX-4 increases histone acetylase activity and reverses epigenetic modifications that silence PDX1 in the intrauterine growth retarded rat (Pinney et al., 2011). Although adiposity was not examined in this study, GLPs are known to modify food intake, increase satiety, delay gastric emptying, and suppress glucagon release and therefore further studies are needed to explore these signaling pathways.

The role of possible direct nutritional interventions has been highlighted in a study by Wyrwoll et al. (2006). Pregnant rats were treated with synthetic glucocorticoids (Dexamethasone; DEX) from embryonic day 13 to term; offspring were cross-fostered to mothers on either a standard diet or a diet high in omega-3 fatty acids, pups remained on these diets post-weaning. Maternal DEX reduced birthweight and delayed the onset of puberty in offspring and elicited hyperleptinemia and increased fat mass in offspring by 6 months of age. These effects were ameliorated by a high omega3 diet, demonstrating that direct manipulation of postnatal diet, other than that associated with postnatal caloric restriction, can limit adverse outcomes of maternal glucocorticoid administration.

The use of taurine supplementation either during pregnancy and/or lactation has long been known to be efficacious in preventing pancreatic $\beta$-cell dysregulation and restoring normal proliferation and apoptosis of rat pancreatic islets following a MLP diet (Boujendar et al., 2002). The mechanism by which taurine regulates the apoptotic rate of endocrine cells involving IGF-II and Fas signaling pathways (Boujendar et al., 2002) are not completely understood. Maternal LP diet leads to underexpression of VEGF and Flk-1, associated with the lower fetal islet vascularization; maternal supplementation with taurine prevented such damage and may have a potential role in islet vasculogenesis (Boujendar et al., 2003). Recent findings suggest that a maternal LP diet causes long-lasting mitochondrial changes, which may contribute to the development of type 2 diabetes later in life, and that a lack of taurine may be a key causative factor for these dysfunctional mitochondrial changes (Lee et al., 2011); it may be through this route that taurine serves also to regulate DNA synthesis.

\section{PHYSICAL ACTIVITY AND EXERCISE AS AN INTERVENTION}

Most of the investigations of developmental programming have focused on metabolic and cardiovascular disorders and little attention has been paid to indices such as physical activity and effects of exercise. The studies that have examined activity have primarily focused on stress and anxiety behaviors, not direct physical activity per se. Clinical and epidemiological studies of changes in physical activity resulting from a poor fetal environment are limited and it appears that two main factors have contributed to this limitation: first, lifestyle influences obscure linkages between metabolic predisposition and maturity onset behavioral patterns; and second, the need to use subject diaries, that describe perceived activity levels in clinical cohorts have inherent errors in the precision of reporting. Epidemiological studies of survivors of the Dutch famine of 1944-1945 have shown that prenatal exposure to famine resulted in not only altered food preferences toward unhealthy diets but also showed trends toward reduced physical activity in adulthood (Lussana et al., 2008).

A number of recent reports in animal models suggest that several aspects of physical activity are determined by factors operating in early life. Studies in rats, using a variety of maternal manipulations, have shown that voluntary locomotor behavior is significantly reduced in offspring in postnatal life. Maternal undernutrition in the rat resulted in reduced physical activity before the development of an obese phenotype with programming-induced alterations in physical activity levels being reported as early as postnatal day 35 (pubertal age; Vickers et al., 2003). Similarly, a maternal LP diet has been shown to result in a significant reduction in voluntary locomotor activity in offspring (Bellinger et al., 2006; Langley-Evans, 2007). The window of LP exposure is critical in determining effects on locomotor activity in offspring and sometimes manifests in a gender-specific manner. In the mouse, preconceptional LP feeding during one female ovulatory cycle prior to natural mating led to a reduction in locomotor activity in offspring (Watkins et al., 2008). In the mouse, maternal diet-induced obesity leads to a reduction in physical activity in offspring (Samuelsson et al., 2008).

Despite growing evidence for the developmental programming of sedentary behavior, little is known about the effect of exercise as a maternal intervention. Any programming-induced compromise in the control of resting metabolism, either through deficits in oxidative fiber number or intramuscular energy sensing could act as the initial trigger for increased susceptibility to developing the metabolic syndrome (Nassis et al., 2005; Gardner and Rhodes, 2009). It has been suggested that as little as regular low-moderate intensity exercise, independent of any reduction in bodyweight, is needed to prevent the development of metabolic disorders in offspring (e.g., via activation of muscle-specific PGC-1 for example; Arany et al., 2007; Gardner and Rhodes, 2009). Using a rat 
model, Miles et al. (2009a) showed prenatally undernourished rats increased their preference for wheel running versus lever pressing for food in a choice task. Further, despite a predisposition to develop obesity under sedentary conditions, obesity development was prevented in IUGR offspring when exercise was available (Miles et al., 2009b).

\section{ROLE OF EPIGENETICS}

Epigenetics is the study of heritable changes in gene expression or cellular phenotype caused by mechanisms other than changes in the underlying DNA sequence (Henikoff and Matzke, 1997). Because of their inherent malleability, epigenetic mechanisms are susceptible to environmental influences and this environmental susceptibility is expected to be enhanced during early development. As such, this process is emerging as an important regulator of the changes in gene expression undergone by adipose tissue during obesity. Importantly, epigenetic marks may be reprogrammed in response to both stochastic and environmental stimuli, such as changes in diet and the in utero environment (Jaenisch and Bird, 2003).

Within tissues and organs that control metabolic homeostasis, a range of phenotypes can be induced by sustained changes in maternal diet via modulation of genes that control DNA methylation and by histone acetylation, which suggests epigenetic programming (Sebert et al., 2011). Leptin's 3-kb promoter region is embedded within a $\mathrm{CpG}$ island and contains many putative binding sites for known transcription factors, such as Sp-1 sites, cAMP response element, glucocorticoid response element, and a functional CCAAT/enhancer binding protein $(\mathrm{C} / \mathrm{EBP}-\alpha)$ site which contains a CG dinucleotide and is sufficient for tissue-specific gene expression (Gong et al., 1996; Stoger, 2006). It has been shown that leptin's promoter is subject to epigenetic programming and leptin's expression can be modulated by DNA methylation.

Such potential mechanisms underlying epigenetic modification of tissue function resulting in a predisposition to altered leptin and insulin signaling are discussed by Holness and Sugden (2006). For example, activation of the leptin receptor induced expression of suppressor of cytokine signaling-3 (SOCS-3). This protein inhibits leptin signal transduction and also potently inhibits insulin receptor signaling. Altered SOCS-3 methylation may therefore have lasting effects on the leptin-insulin feedback loop; the adipoinsular axis (Kieffer and Habener, 2000). Impaired glucose tolerance during pregnancy is associated with altered leptin gene DNA methylation with potential functional impacts (Bouchard et al., 2010). In patients analyzed before and after bariatric surgeryinduced weight loss, a decrease in WAT leptin expression (about $50 \%$ ) did not correspond to changes in promoter methylation density. Thus, methylation density in the leptin promoter may constitute one control level for cell-type specific leptin expression, whereas weight loss induced changes in leptin expression does not appear to be methylation-dependent (Marchi et al., 2011).

Fixed genomic variation explains only a small proportion of the risk of adiposity. In animal models, maternal diet alters offspring body composition, accompanied by epigenetic changes in metabolic control genes. Little is known about whether such processes operate in humans (Godfrey et al., 2011). Recent work has shown the utility for perinatal epigenetic analysis in identifying individual vulnerability to later obesity and metabolic disease (Godfrey et al., 2011). In this study, epigenetic gene promoter methylation at birth was associated with adiposity in children. Identification of in vivo methylation of the leptin promoter provides a molecular entry point to study the timing, factors, and conditions that lead to tissue-specific methylation patterns of gene promoters (Stoger, 2006). Overall therefore, the application of epigenomic approaches and the determination of targets (e.g., imprinted or non-imprinted genes and methylation sites) for early life effects on epigenetic gene regulation are exciting and important new areas of investigation (McMillen and Robinson, 2005).

\section{DISCUSSION}

Numerous epidemiological studies have described a relationship between an adverse prenatal environment and the development of metabolic disease and obesity in later life. Both clinical/epidemiological studies and experimental research have clearly shown that the propensity to develop increased adiposity in later life is increased when early life development has been adversely affected. The pathogenesis is not based on genetic defects but on altered genetic expression as a consequence of an adaptation to environmental changes during early life development. However, little is known about the interaction between the pre-and postnatal nutritional environment on either amplification or resolution of the programming phenotype depending on the degree of nutritional match/mismatch. Thus, experiments to examine the PARs hypothesis are required in conjunction with transgenerational work to further the $\mathrm{DOHaD}$ paradigm.

The molecular mechanisms underlying developmental programming have only recently begun to be investigated. Epigenetics has now become a mechanism that is fundamental to research into DOHaD. The two most studied epigenetic mechanisms identified in the adaptive developmental programming of metabolic disorders are DNA methylation and histone modifications. Availability of dietary methyl donors and cofactors during a critical window of fetal development may influence DNA methylation patterns. Thus, early methyl donor malnutrition (i.e., excess nutrition or undernutrition) could effectively lead to premature epigenetic aging (changes in age-associated DNA methylation patterns) and thereby confer an enhanced susceptibility to adult disease in later life (Waterland and Jirtle, 2004).

Developmental programming research offers a novel approach to investigate the mechanistic basis of obesity and related metabolic disorders which in human populations predominantly arises from environmental factors and lifestyle choices. It is notable that the variety of different insults in early life (caloric, protein, iron, fat-fed) produce the same detrimental consequences in adult life, suggestive of a common mechanism underlying the developmental early life programming of adult disease. An increasing number of studies are now investigating avenues to reverse or ameliorate the detrimental metabolic effects associated with developmental programming. Of note, intervention studies with leptin in the early period of developmental plasticity have shown promise in reversing the programmed metabolic phenotype; however translation from small animal models to the human setting is difficult as the critical windows observed in the rodent represent a late period 
of in utero development in larger species. However, the emerging focus on studies aimed at reversing the programmed phenotype offers an exciting potential for new advances in our understanding of critical determinants and mechanisms for human obesity and metabolic disorders.

\section{REFERENCES}

Arany, Z., Lebrasseur, N., Morris, C., Smith, E., Yang, W., Ma, Y., Chin, S., and Spiegelman, B. M. (2007). The transcriptional coactivator PGClbeta drives the formation of oxidative type IIX fibers in skeletal muscle. Cell Metab. 5, 35-46.

Armitage, J. A., Khan, I. Y., Taylor, P. D., Nathanielsz, P. W., and Poston, L. (2004). Developmental programming of the metabolic syndrome by maternal nutritional imbalance: how strong is the evidence from experimental models in mammals? J. Physiol. (Lond.) 561, 355-377.

Armitage, J. A., Taylor, P. D., and Poston, L. (2005). Experimental models of developmental programming: consequences of exposure to an energy rich diet during development. J. Physiol. (Lond.) 565, 3-8.

Attig, L., Larcher, T., Gertler, A., Abdennebi-Najar, L., and Djiane, J. (2011). Postnatal leptin is necessary for maturation of numerous organs in newborn rats. Organogenesis 7, 88-94.

Attig, L., Solomon, G., Ferezou, J., Abdennebi-Najar, L., Taouis, M., Gertler, A., and Djiane, J. (2008a). Early postnatal leptin blockage leads to a long-term leptin resistance and susceptibility to diet-induced obesity in rats. Int. J. Obes. (Lond.) 32, 1153-1160.

Attig, L., Djiane, J., Gertler, A., Rampin, O., Larcher, T., Boukthir, S., Anton, P. M., Madec, J. Y., Gourdou, I., and Abdennebi-Najar, L. (2008b). Study of hypothalamic leptin receptor expression in low-birth-weight piglets and effects of leptin supplementation on neonatal growth and development. Am. J. Physiol. Endocrinol. Metab. 295, E1117E1125.

Bai, S., Briggs, D., and Vickers, M. H. (2012). Increased systolic blood pressure in rat offspring following a maternal low-protein diet is normalized by maternal dietary choline supplementation. J. Dev. Orig. Health Dis. 3, 1-8.

Banks, W. A., Coon, A. B., Robinson, S. M., Moinuddin, A., Shultz, J. M., Nakaoke, R., and Morley, J. E. (2004). Triglycerides induce leptin resistance at the blood-brain barrier. Diabetes 53, 1253-1260.

Barker, D. J. (2007a). Obesity and early life. Obes. Rev. 8(Suppl. 1), 45-49.
Barker, D. J. (2007b). The origins of the developmental origins theory. $J$. Intern. Med. 261, 412-417.

Barker, D. J., Bull, A. R., Osmond, C., and Simmonds, S. J. (1990). Fetal and placental size and risk of hypertension in adult life. BMJ 301, 259-262.

Barker, D. J., Osmond, C., Golding, J., Kuh, D., and Wadsworth, M. E. (1989). Growth in utero, blood pressure in childhood and adult life, and mortality from cardiovascular disease. BMJ 298, 564-567.

Bell, C. G., Walley, A. J., and Froguel, P. (2005). The genetics of human obesity. Nat. Rev. Genet. 6, 221-234.

Bellinger, L., Sculley, D. V., and LangleyEvans, S. C. (2006). Exposure to undernutrition in fetal life determines fat distribution, locomotor activity and food intake in ageing rats. Int. J. Obes. (Lond.) 30, 729-738. L., Truong, M., and Vickers, M. H. (2012). The effect of neonatal leptin antagonism in male rat offspring is dependent upon the interaction between prior maternal nutritional status and post-weaning diet. 2012/296935

Bouchard, L., Thibault, S., Guay, S. P., Santure, M., Monpetit, A., St-Pierre, J., Perron, P., and Brisson, D. (2010). Leptin gene epigenetic adaptation to impaired glucose metabolism during pregnancy. Diabetes Care 33, 2436-2441.

Boujendar, S., Arany, E., Hill, D., Remacle, C., and Reusens, B. (2003). Taurine supplementation of a low protein diet fed to rat dams normalizes the vascularization of the fetal endocrine pancreas. J. Nutr. 133, 2820-2825.

Boujendar, S., Reusens, B., Merezak, S., Ahn, M. T., Arany, E., Hill, D., and Remacle, C. (2002). Taurine supplementation to a low protein diet during foetal and early postnatal life restores a normal proliferation and apoptosis of rat pancreatic islets. Diabetologia 45, 856-866.

Bouret, S. G., Draper, S. J., and Simerly, R. B. (2004a). Trophic action of leptin on hypothalamic neurons that regulate feeding. Science 304 , 108-110.

Bouret, S. G., Draper, S. J., and Simerly, R. B. (2004b). Formation of projection pathways from the
Beltrand, J., Sloboda, D. M., Connor, K. J. Nutr. Metab. 2012. doi:10.1155/

\section{ACKNOWLEDGMENTS}

The authors acknowledge funding support from the Health Research Council of New Zealand, the National Research Centre for Growth and Development, the Kelliher Charitable Trust, and the Ministry of Science and Innovation.

arcuate nucleus of the hypothalamus to hypothalamic regions implicated in the neural control of feeding behavior in mice. J. Neurosci. 24, 2797-2805.

Bouret, S. G., and Simerly, R. B. (2004). Minireview: leptin and development of hypothalamic feeding circuits. Endocrinology 145, 2621-2626.

Breier, B. H., Vickers, M. H., Ikenasio, B. A., Chan, K. Y., and Wong, W. P. (2001). Fetal programming of appetite and obesity. Mol. Cell. Endocrinol. 185, 73-79.

Chan, J. L., Lutz, K., Cochran, E., Huang, W., Peters, Y., Weyer, C., and Gorden, P. (2011). Clinical effects of long-term metreleptin treatment in patients with lipodystrophy. Endocr. Pract. 17, 922-932.

Chmurzynska, A., Stachowiak, M., and Pruszynska-Oszmalek, E. (2011) Maternal protein and folic acid intake during gestation does not program leptin transcription or serum concentration in rat progeny. Genes Nutr. 7, 217-222.

Cogswell, M. E., Parvanta, I., Ickes, L., Yip, R., and Brittenham, G. M. (2003). Iron supplementation during pregnancy, anemia, and birth weight: a randomized controlled trial. Am. J. Clin. Nutr. 78, 773-781.

Dahlgren, J., Nilsson, C., Jennische, E. Ho, H. P., Eriksson, E., Niklasson, A., Bjorntorp, P., Albertsson Wikland, K., and Holmang, A. (2001). Prenatal cytokine exposure results in obesity and gender-specific programming. Am. J. Physiol. Endocrinol. Metab. 281, E326-E334.

Desai, M., Crowther, N. J., Lucas, A., and Hales, C. N. (1996). Organ-selective growth in the offspring of proteinrestricted mothers. Br. J. Nutr. 76, 591-603.

Desai, M., Gayle, D., Babu, J., and Ross, M. G. (2005). Programmed obesity in intrauterine growthrestricted newborns: modulation by newborn nutrition. Am. J. Physiol Regul. Integr. Comp. Physiol. 288, R91-R96.

Elmquist, J. K., Ahima, R. S., Elias, C. F., Flier, J. S., and Saper, C. B. (1998). Leptin activates distinct projections from the dorsomedial and ventromedial hypothalamic nuclei. Proc. Natl. Acad. Sci. U.S.A. 95, 741-746.

Eriksson, J., Forsen, T., Osmond, C., and Barker, D. (2003). Obesity from cradle to grave. Int. J. Obes. Relat Metab. Disord. 27, 722-727.

Eriksson, J. G., Forsen, T., Tuomilehto, J., Winter, P. D., Osmond, C. and Barker, D. J. (1999). Catch-up growth in childhood and death from coronary heart disease: longitudinal study. BMJ 318, 427-431.

Ferezou-Viala, J., Roy, A. F., Serougne, C., Gripois, D., Parquet, M., Bailleux, V., Gertler, A., Delplanque, B., Diiane, J., Riottot, M., and Taouis, M. (2007). Long-term consequences of maternal high-fat feeding on hypothalamic leptin sensitivity and dietinduced obesity in the offspring. Am. J. Physiol. Regul. Integr. Comp. Physiol. 293, R1056-R1062.

Gambling, L., Dunford, S., Wallace, D. I., Zuur, G., Solanky, N., Srai, S. K., and McArdle, H. J. (2003). Iron deficiency during pregnancy affects postnatal blood pressure in the rat. J. Physiol. (Lond.) 552, 603-610.

Garcia, A. P., Palou, M., Sanchez, J., Priego, T., Palou, A., and Pico, C. (2011). Moderate caloric restriction during gestation in rats alters adipose tissue sympathetic innervation and later adiposity in offspring. PLoS ONE 6, e17313. doi:10.1371/journal.pone.0017313

Gardner, D. S., and Rhodes, P. (2009). Early Nutriton Programming and Health Outcomes in Later Life: Obesity and Beyond. New York: Springer Science.

Glavas, M. M., Kirigiti, M. A., Xiao, X. Q., Enriori, P. J., Fisher, S. K., Evans, A. E., Grayson, B. E., Cowley, M. A., Smith, M. S., and Grove, K. L. (2010). Early overnutrition results in early onset arcuate leptin resistance and increased sensitivity to high-fat diet. Endocrinology 151, 1598-1610.

Gluckman, P. D., Beedle, A. S., Hanson, M. A., and Vickers, M. (2007). Leptin reversal of the metabolic phenotype: evidence for the role of developmental plasticity in the development of the metabolic syndrome. Horm. Res. 67, 115-120.

Gluckman, P. D., and Hanson, M. A. (2004a). Developmental origins of disease paradigm: a mechanistic and evolutionary perspective. Pediatr. Res. 56, 311-317.

Gluckman, P. D., and Hanson, M. A. (2004b). Living with the past: evolution, development, and patterns of disease. Science 305, 1733-1736. 
Gluckman, P. D., Hanson, M. A., Beedle, A. S., and Spencer, H. G. (2008). Predictive adaptive responses in perspective. Trends Endocrinol. Metab. 19, 109-110.

Godfrey, K. M., and Barker, D. J. (2000). Fetal nutrition and adult disease. Am. J. Clin. Nutr. 71, 1344S-1352S.

Godfrey, K. M., Sheppard, A., Gluckman, P. D., Lillycrop, K. A., Burdge, G. C., McLean, C., Rodford, J., SlaterJefferies, J. L., Garratt, E., Crozier, S. R., Emerald, B. S., Gale, C. R., Inskip, H. M., Cooper, C., and Hanson, M. A. (2011). Epigenetic gene promoter methylation at birth is associated with child's later adiposity. Diabetes 60, 1528-1534.

Gong, D. W., Bi, S., Pratley, R. E., and Weintraub, B. D. (1996). Genomic structure and promoter analysis of the human obese gene. J. Biol. Chem. 271, 3971-3974.

Grasso, P. (2011). Novel approaches to the treatment of obesity and type 2 diabetes mellitus: bioactive leptinrelated synthetic peptide analogs. Recent Pat. Endocr. Metab. Immune Drug Discov. 5, 163-175.

Henikoff, S., and Matzke, M. A. (1997). Exploring and explaining epigenetic effects. Trends Genet. 13, 293-295.

Hofbauer, K. G. (2002). Molecular pathways to obesity. Int. J. Obes. Relat. Metab. Disord. 26(Suppl. 2), S18S27.

Holemans, K., Caluwaerts, S., Poston, L., and Van Assche, F. A. (2004). Diet-induced obesity in the rat: a model for gestational diabetes mellitus. Am. J. Obstet. Gynecol. 190, 858-865.

Holness, M. J., and Sugden, M. C. (2006). Epigenetic regulation of metabolism in children born small for gestational age. Curr. Opin. Clin. Nutr. Metab. Care 9, 482-488.

Horvath, T. L., and Bruning, J. C. (2006). Developmental programming of the hypothalamus: a matter of fat. Nat. Med. 12, 52-53; discussion 53.

Howie, G. J., Sloboda, D. M., Kamal, T., and Vickers, M. H. (2009). Maternal nutritional history predicts obesity in adult offspring independent of postnatal diet. J. Physiol. (Lond.) 587, 905-915.

Howie, G. J., Sloboda, D. M., and Vickers, M. H. (2011). Maternal undernutrition during critical windows of development results in differential and sex-specific effects on postnatal adiposity and related metabolic profiles in adult rat offspring. Br. J. Nutr. $11,1-10$.

Iniguez, G., Soto, N., Avila, A., Salazar, T., Ong, K., Dunger, D., and Mericq, V. (2004). Adiponectin levels in the first two years of life in a prospective cohort: relations with weight gain, leptin levels and insulin sensitivity. J. Clin. Endocrinol. Metab. 89, 5500-5503.

Itoh, H., Yura, S., Sagawa, N., Kanayama, N., and Konihi, I. (2011). Neonatal exposure to leptin reduces glucose tolerance in adult mice. Acta Physiol. (Oxf.) 202, 159-164.

Jackson, A. A., Dunn, R. L., Marchand, M. C., and Langley-Evans, S. C. (2002). Increased systolic blood pressure in rats induced by a maternal low-protein diet is reversed by dietary supplementation with glycine. Clin. Sci. 103, 633-639.

Jaenisch, R., and Bird, A. (2003). Epigenetic regulation of gene expression: how the genome integrates intrinsic and environmental signals. Nat. Genet. 33(Suppl.) 245-254.

Jennings, B. J., Ozanne, S. E., Dorling, M. W., and Hales, C. N. (1999). Early growth determines longevity in male rats and may be related to telomere shortening in the kidney. FEBS Lett. 448, 4-8.

Kieffer, T. J., and Habener, J. F. (2000). The adipoinsular axis: effects of leptin on pancreatic beta-cells. Am. J. Physiol. Endocrinol. Metab. 278, E1E14.

Krechowec, S. O., Vickers, M., Gertler, A., and Breier, B. H. (2006). Prenatal influences on leptin sensitivity and susceptibility to diet-induced obesity. J. Endocrinol. 189, 355-363.

Ladyman, S. R., Augustine, R. A., and Grattan, D. R. (2010). Hormone interactions regulating energy balance during pregnancy. J. Neuroendocrinol. 22, 805-817.

Langley, S. C., and Jackson, A. A. (1994). Increased systolic blood pressure in adult rats induced by fetal exposure to maternal low protein diets. Clin. Sci. 86, 217-222; discussion 121.

Langley-Evans, S. C. (2000). Critical differences between two low protein diet protocols in the programming of hypertension in the rat. Int. J. Food Sci. Nutr. 51, 11-17.

Langley-Evans, S. C. (2007). Metabolic programming in pregnancy: studies in animal models. Genes Nutr. 2, 33-38.

Langley-Evans, S. C., Welham, S. J., and Jackson, A. A. (1999). Fetal exposure to a maternal low protein diet impairs nephrogenesis and promotes hypertension in the rat. Life Sci. 64, 965-974.

Law, C. M., Barker, D. J., Osmond, C., Fall, C. H., and Simmonds, S. J. (1992). Early growth and abdominal fatness in adult life. J. Epidemiol. Community Health 46, 184-186.
Lee, Y. Y., Lee, H. J., Lee, S. S., Koh, J. S., Jin, C. J., Park, S. H., Yi, K. H., Park, K. S., and Lee, H. K. (2011). Taurine supplementation restored the changes in pancreatic islet mitochondria in the fetal protein-malnourished rat. Br. J. Nutr. 106, 1198-1206.

Lewis, R. M., Forhead, A. J., Petry, C. J., Ozanne, S. E., and Hales, C. N. (2002). Long-term programming of blood pressure by maternal dietary iron restriction in the rat. Br. J. Nutr. 88, 283-290.

Lewis, R. M., Petry, C. J., Ozanne, S. E. and Hales, C. N. (2001). Effects of maternal iron restriction in the rat on blood pressure, glucose tolerance, and serum lipids in the 3-monthold offspring. Metab. Clin. Exp. 50, 562-567.

Lillycrop, K. A., Phillips, E. S., Jackson, A. A., Hanson, M. A., and Burdge, G. C. (2005). Dietary protein restriction of pregnant rats induces and folic acid supplementation prevents epigenetic modification of hepatic gene expression in the offspring. $J$. Nutr. 135, 1382-1386.

Lopez, M., Tovar, S., Vazquez, M. J., Nogueiras, R., Seoane, L. M., Garcia, M., Senaris, R. M., and Dieguez, C. (2007). Perinatal overfeeding in rats results in increased levels of plasma leptin but unchanged cerebrospinal leptin in adulthood. Int. J. Obes. (Lond.) 31, 371-377.

Lussana, F., Painter, R. C., Ocke, M. C., Buller, H. R., Bossuyt, P. M., and Roseboom, T. J. (2008). Prenatal exposure to the Dutch famine is associated with a preference for fatty foods and a more atherogenic lipid profile. Am. J. Clin. Nutr. 88, 1648-1652.

Mantzoros, C. S., Magkos, F., Brinkoetter, M., Sienkiewicz, E., Dardeno, T. A., Kim, S. Y., Hamnvik, O. P., and Koniaris, A. (2011). Leptin in human physiology and pathophysiology. Am. J. Physiol. Endocrinol. Metab. 301, E567-E584.

Marchi, M., Lisi, S., Curcio, M., Barbuti, S., Piaggi, P., Ceccarini, G., Nannipieri, M., Anselmino, M., Di Salvo, C., Vitti, P., Pinchera, A., Santini, F., and Maffei, M. (2011). Human leptin tissue distribution, but not weight lossdependent change in expression, is associated with methylation of its promoter. Epigenetics 6, 1198-1206.

McArdle, H. J., Andersen, H. S., Jones, H., and Gambling, L. (2006). Fetal programming: causes and consequences as revealed by studies of dietary manipulation in rats - a review. Placenta 27(Suppl. A), S56S60.
McMillen, I. C., Adam, C. L., and Muhlhausler, B. S. (2005). Early origins of obesity: programming the appetite regulatory system. J. Physiol. (Lond.) 565, 9-17.

McMillen, I. C., and Robinson, J. S (2005). Developmental origins of the metabolic syndrome: prediction, plasticity, and programming. Physiol. Rev. 85, 571-633.

Miles, J. L., Landon, J., Davison, M., Krageloh, C. U., Thompson, N. M., Triggs, C. M., and Breier, B. H. (2009a). Prenatally undernourished rats show increased preference for wheel running v. lever pressing for food in a choice task. Br. J. Nutr. 101, 902-908.

Miles, J. L., Huber, K., Thompson, N. M., Davison, M., and Breier, B. H. (2009b). Moderate daily exercise activates metabolic flexibility to prevent prenatally induced obesity. Endocrinology 150, 179-186.

Mistry, A. M., Swick, A., and Romsos, D. R. (1999). Leptin alters metabolic rates before acquisition of its anorectic effect in developing neonatal mice. Am. J. Physiol. 277, R742R747.

Morris, M. J., and Chen, H. (2009). Established maternal obesity in the rat reprograms hypothalamic appetite regulators and leptin signaling at birth. Int. J. Obes. (Lond.) 33, 115-122.

Morris, T. J., Vickers, M., Gluckman, P., Gilmour, S., and Affara, N. (2009). Transcriptional profiling of rats subjected to gestational undernourishment: implications for the developmental variations in metabolic traits. PLoS ONE 4, e7271. doi:10.1371/journal.pone.0007271

Muhlhausler, B. S., Adam, C. L., and McMillen, I. C. (2008). Maternal nutrition and the programming of obesity: the brain. Organogenesis 4, 144-152.

Nassis, G. P., Papantakou, K., Skenderi, K., Triandafillopoulou, M. Kavouras, S. A., Yannakoulia, M., Chrousos, G. P., and Sidossis, L. S. (2005). Aerobic exercise training improves insulin sensitivity without changes in body weight, body fat, adiponectin, and inflammatory markers in overweight and obese girls. Metab. Clin. Exp. 54, 1472-1479.

Nyirenda, M. J., Lindsay, R. S., Kenyon, C. J., Burchell, A., and Seckl, J. R. (1998). Glucocorticoid exposure in late gestation permanently programs rat hepatic phosphoenolpyruvate carboxykinase and glucocorticoid receptor expression and causes glucose intolerance in 
adult offspring. J. Clin. Invest. 101, 2174-2181.

Ong, K. K., Ahmed, M. L., Emmett, P. M., Preece, M. A., and Dunger, D. B. (2000). Association between postnatal catch-up growth and obesity in childhood: prospective cohort study. BMJ 320, 967-971.

Osmond, C., Barker, D. J., and Slattery, J. M. (1990). Risk of death from cardiovascular disease and chronic bronchitis determined by place of birth in England and Wales. J. Epidemiol. Community Health 44, 139-141.

Ozaki, T., Hawkins, P., Nishina, H., Steyn, C., Poston, L., and Hanson, M. A. (2000). Effects of undernutrition in early pregnancy on systemic small artery function in late-gestation fetal sheep. Am. J. Obstet. Gynecol. 183, 1301-1307.

Ozanne, S. E. (2011). Sugaring appetite development: mechanisms of neuroendocrine programming. Endocrinology 152, 4007-4009.

Ozanne, S. E., Wang, C. L., Dorling, M. W., and Petry, C. J. (1999). Dissection of the metabolic actions of insulin in adipocytes from early growth-retarded male rats. $J$. Endocrinol. 162, 313-319.

Padmavathi, I. J., Rao, K. R., Venu, L., Ganeshan, M., Kumar, K. A., Rao Ch, N., Harishankar, N., Ismail, A., and Raghunath, M. (2010a). Chronic maternal dietary chromium restriction modulates visceral adiposity: probable underlying mechanisms. Diabetes 59, 98-104.

Padmavathi, I. J., Rao, K. R., Venu, L., Ismail, A., and Raghunath, M. (2010b). Maternal dietary chromium restriction programs muscle development and function in the rat offspring. Exp. Biol. Med. 235, 349-355.

Palou, M., Priego, T., Sanchez, J., Palou, A., and Pico, C. (2010). Sexual dimorphism in the lasting effects of moderate caloric restriction during gestation on energy homeostasis in rats is related with fetal programming of insulin and leptin resistance. Nutr. Metab. (Lond) 7, 69.

Park, J. H., Stoffers, D. A., Nicholls, R. D., and Simmons, R. A. (2008). Development of type 2 diabetes following intrauterine growth retardation in rats is associated with progressive epigenetic silencing of Pdx1. J. Clin. Invest. 118, 2316-2324.

Parsons, T. J., Power, C., and Manor, O. (2001). Fetal and early life growth and body mass index from birth to early adulthood in 1958 British cohort: longitudinal study. BMJ 323 , 1331-1335.
Petry, C. J., Dorling, M. W., Pawlak, D. B., Ozanne, S. E., and Hales, C. N. (2001). Diabetes in old male offspring of rat dams fed a reduced protein diet. Int. J. Exp. Diabetes Res. 2, 139-143.

Pico, C., Jilkova, Z. M., Kus, V., Palou, A., and Kopecky, J. (2011). Perinatal programming of body weight control by leptin: putative roles of AMP kinase and muscle thermogenesis. Am. J. Clin. Nutr. 94, 1830S-1837S.

Pico, C., Oliver, P., Sanchez, J., Miralles, O., Caimari, A., Priego, T., and Palou, A. (2007). The intake of physiological doses of leptin during lactation in rats prevents obesity in later life. Int. J. Obes. (Lond.) 31, 1199-1209.

Pinney, S. E., Jaeckle Santos, L. J., Han, Y., Stoffers, D. A., and Simmons, R. A. (2011). Exendin-4 increases histone acetylase activity and reverses epigenetic modifications that silence Pdx 1 in the intrauterine growth retarded rat. Diabetologia 54, 2606-2614.

Plagemann, A. (2006). Perinatal nutrition and hormone-dependent programming of food intake. Horm. Res. 65(Suppl. 3), 83-89.

Plagemann, A., Harder, T., Rake, A., Voits, M., Fink, H., Rohde, W., and Dorner, G. (1999). Perinatal elevation of hypothalamic insulin, acquired malformation of hypothalamic galaninergic neurons, and syndrome $x$-like alterations in adulthood of neonatally overfed rats. Brain Res. 836, 146-155.

Raab, E. L., Vuguin, P. M., Stoffers, D. A., and Simmons, R. A. (2009). Neonatal exendin-4 treatment reduces oxidative stress and prevents hepatic insulin resistance in intrauterine growth retarded rats. Am. J. Physiol. Regul. Integr. Comp. Physiol. 297, R1785-R1794.

Rajakumar, P. A., He, J., Simmons, R. A., and Devaskar, S. U. (1998). Effect of uteroplacental insufficiency upon brain neuropeptide $\mathrm{Y}$ and corticotropin-releasing factor gene expression and concentrations. Pediatr. Res. 44, 168-174.

Ravelli, A. C., van Der Meulen, J. H., Osmond, C., Barker, D. J., and Bleker, O. P. (1999). Obesity at the age of $50 \mathrm{y}$ in men and women exposed to famine prenatally. Am. J. Clin. Nutr. $70,811-816$.

Ravelli, G. P., Stein, Z. A., and Susser, M. W. (1976). Obesity in young men after famine exposure in utero and early infancy. N. Engl. J. Med. 295, 349-353.

Roseboom, T. J., van der Meulen, J. H., Ravelli, A. C., Osmond, C., Barker, D. J., and Bleker, O. P. (2001). Effects of prenatal exposure to the Dutch famine on adult disease in later life: an overview. Mol. Cell. Endocrinol. 185, 93-98.

Roseboom, T. J., van der Meulen, J. H., Ravelli, A. C., van Montfrans, G. A., Osmond, C., Barker, D. J., and Bleker, O. P. (1999). Blood pressure in adults after prenatal exposure to famine. $J$. Hypertens. 17, 325-330.

Samuelsson, A. M., Matthews, P. A., Argenton, M., Christie, M. R., McConnell, J. M., Jansen, E. H., Piersma, A. H., Ozanne, S. E. Twinn, D. F., Remacle, C., Rowlerson, A., Poston, L., and Taylor, P. D. (2008). Diet-induced obesity in female mice leads to offspring hyperphagia, adiposity, hypertension, and insulin resistance: a novel murine model of developmental programming. Hypertension 51, 383-392.

Savino, F., Fissore, M. F., Liguori, S. A., and Oggero, R. (2009). Can hormones contained in mothers' milk account for the beneficial effect of breast-feeding on obesity in children? Clin. Endocrinol. (Oxf.) 71, 757-765.

Schulz, C., Paulus, K., Johren, O., and Lehnert, H. (2011). Intranasal leptin reduces appetite and induces weight loss in rats with diet-induced obesity (DIO). Endocrinology 15391, 143-153.

Sebert, S., Sharkey, D., Budge, H., and Symonds, M. E. (2011). The early programming of metabolic health: is epigenetic setting the missing link? Am. J. Clin. Nutr. 94, 1953S-1958S.

Shin, B. C., Dai, Y., Thamotharan, M., Gibson, L. C., and Devaskar S. U. (2012). Pre- and postnatal calorie restriction perturbs early hypothalamic neuropeptide and energy balance. J. Neurosci. Res. 90, 1169-1182.

Simmons, R. A., Templeton, L. J., and Gertz, S. J. (2001). Intrauterine growth retardation leads to the development of type 2 diabetes in the rat. Diabetes 50, 2279-2286.

Snoeck, A., Remacle, C., Reusens, B. and Hoet, J. J. (1990). Effect of a low protein diet during pregnancy on the fetal rat endocrine pancreas. Biol. Neonate 57, 107-118.

Sorensen, A., Mayntz, D., Raubenheimer, D., and Simpson, S. J. (2008). Protein-leverage in mice: the geometry of macronutrient balancing and consequences for fat deposition. Obesity (Silver Spring) 16, 566-571.

Stanner, S. A., and Yudkin, J. S. (2001). Fetal programming and the Leningrad Siege study. Twin Res. 4, 287-292.

Stocker, C., O'Dowd, J., Morton, N. M., Wargent, E., Sennitt, M. V., Hislop,
D., Glund, S., Seckl, J. R., Arch, J. R., and Cawthorne, M. A. (2004). Modulation of susceptibility to weight gain and insulin resistance in low birthweight rats by treatment of their mothers with leptin during pregnancy and lactation. Int. J. Obes. Relat. Metab. Disord. 28, 129-136.

Stocker, C. J., Wargent, E., O'Dowd, J., Cornick, C., Speakman, J. R., Arch, J. R., and Cawthorne, M. A. (2007). Prevention of diet-induced obesity and impaired glucose tolerance in rats following administration of leptin to their mothers. Am. J. Physiol. Regul. Integr. Comp. Physiol. 292, R1810-R1818.

Stoffers, D. A., Desai, B. M., DeLeon, D. D., and Simmons, R. A. (2003). Neonatal exendin-4 prevents the development of diabetes in the intrauterine growth retarded rat. Diabetes 52, 734-740.

Stoger, R. (2006). In vivo methylation patterns of the leptin promoter in human and mouse. Epigenetics 1, 155-162.

Szeto, I. M., Aziz, A., Das, P. J., Taha, A. Y., Okubo, N., Reza-Lopez, S., Giacca, A., and Anderson, G. H. (2008). High multivitamin intake by Wistar rats during pregnancy results in increased food intake and components of the metabolic syndrome in male offspring. Am. J. Physiol. Regul. Integr. Comp. Physiol. 295, R575-R582.

Toste, F. P., de Moura, E. G., Lisboa, P. C., Fagundes, A. T., de Oliveira, E., and Passos, M. C. (2006). Neonatal leptin treatment programmes leptin hypothalamic resistance and intermediary metabolic parameters in adult rats. Br. J. Nutr. 95, 830-837.

Ucar, B., Kirel, B., Bor, O., Kilic, F. S., Dogruel, N., Aydogdu, S. D., and Tekin, N. (2000). Breast milk leptin concentrations in initial and terminal milk samples: relationships to maternal and infant plasma leptin concentrations, adiposity, serum glucose, insulin, lipid and lipoprotein levels. J. Pediatr. Endocrinol. Metab. 13, 149-156.

Venu, L., Harishankar, N., Prasanna Krishna, T., and Raghunath, M. (2004). Maternal dietary vitamin restriction increases body fat content but not insulin resistance in WNIN rat offspring up to 6 months of age. Diabetologia 47, 1493-1501.

Venu, L., Kishore, Y. D., and Raghunath, M. (2005). Maternal and perinatal magnesium restriction predisposes rat pups to insulin resistance and glucose intolerance. J. Nutr. 135 , 1353-1358. 
Vickers, M. H. (2007). Developmental programming of adult obesity: the role of leptin. Curr. Opin. Endocrinol. Diabetes Obes. 14, 17-22.

Vickers, M. H., Breier, B. H., Cutfield, W. S., Hofman, P. L., and Gluckman, P. D. (2000). Fetal origins of hyperphagia, obesity, and hypertension and postnatal amplification by hypercaloric nutrition. Am. J. Physiol. Endocrinol. Metab. 279, E83-E87.

Vickers, M. H., Breier, B. H., McCarthy, D., and Gluckman, P. D. (2003). Sedentary behavior during postnatal life is determined by the prenatal environment and exacerbated by postnatal hypercaloric nutrition. Am. J. Physiol. Regul. Integr. Comp. Physiol. 285, R271-R273.

Vickers, M. H., Gluckman, P. D., Coveny, A. H., Hofman, P. L., Cutfield, W. S., Gertler, A., Breier, B. H., and Harris, M. (2005). Neonatal leptin treatment reverses developmental programming. Endocrinology 146, 4211-4216.

Vickers, M. H., Gluckman, P. D., Coveny, A. H., Hofman, P. L., Cutfield, W. S., Gertler, A., Breier, B. H., and Harris, M. (2008). The effect of neonatal leptin treatment on postnatal weight gain in male rats is dependent on maternal nutritional status during pregnancy. Endocrinology 149, 1906-1913.

Vickers, M. H., Ikenasio, B. A., and Breier, B. H. (2001). IGF-I treatment reduces hyperphagia, obesity, and hypertension in metabolic disorders induced by fetal programming. Endocrinology 142, 3964-3973.

Vickers, M. H., Ikenasio, B. A., and Breier, B. H. (2002). Adult growth hormone treatment reduces hypertension and obesity induced by an adverse prenatal environment. J. Endocrinol. 175, 615-623.

Waterland, R. A., and Jirtle, R. L. (2004). Early nutrition, epigenetic changes at transposons and imprinted genes, and enhanced susceptibility to adult chronic diseases. Nutrition 20, 63-68.

Watkins, A. J., Wilkins, A., Cunningham, C., Perry, V. H., Seet, M. J., Osmond, C., Eckert, J. J., Torrens, C., Cagampang, F. R., Cleal, J., Gray, W. P., Hanson, M. A., and Fleming, T. P. (2008). Low protein diet fed exclusively during mouse oocyte maturation leads to behavioural and cardiovascular abnormalities in offspring. J. Physiol. (Lond.) 586, 2231-2244.

Woodall, S. M., Breier, B. H., Johnston, B. M., and Gluckman, P. D. (1996a). A model of intrauterine growth retardation caused by chronic maternal undernutrition in the rat: effects on the somatotrophic axis and postnatal growth. J. Endocrinol. 150, 231-242.

Woodall, S. M., Johnston, B. M., Breier, B. H., and Gluckman, P. D. (1996b). Chronic maternal undernutrition in the rat leads to delayed postnatal growth and elevated blood pressure of offspring. Pediatr. Res. 40 438-443.

Wyrwoll, C. S., Mark, P. J., Mori, T. A., Puddey, I. B., and Waddell, B. J. (2006). Prevention of programmed hyperleptinemia and hypertension by postnatal dietary omega-3 fatty acids. Endocrinology 147, 599-606.

Yajnik, C. (2000). Interactions of perturbations in intrauterine growth and growth during childhood on the risk of adult-onset disease. Proc. Nutr. Soc. 59, 257-265.

Yura, S., Itoh, H., Sagawa, N., Yamamoto, H., Masuzaki, H., Nakao, K., Kawamura, M., Takemura, M., Kakui, K.,
Ogawa, Y., and Fujii, S. (2005). Role of premature leptin surge in obesity resulting from intrauterine undernutrition. Cell Metab. 1, 371-378.

Conflict of Interest Statement: The authors declare that the research was conducted in the absence of any commercial or financial relationships that could be construed as a potential conflict of interest.

Received: 05 April 2012; accepted: 13 June 2012; published online: 02 July 2012.

Citation: Vickers $M H$ and Sloboda DM (2012) Strategies for reversing the effects of metabolic disorders induced as a consequence of developmental programming. Front. Physio. 3:242. doi: 10.3389/fphys.2012.00242

This article was submitted to Frontiers in Integrative Physiology, a specialty of Frontiers in Physiology.

Copyright (c) 2012 Vickers and Sloboda. This is an open-access article distributed under the terms of the Creative Commons Attribution Non Commercial License, which permits non-commercial use, distribution, and reproduction in other forums, provided the original authors and source are credited. 